WENTZEL VAN HUYSSTEEN:

\title{
TELLING THE STORY OF RELIGIOUS AWARENESS WITH INTER-DISCIPLINARY INTEGRITY FROM AN EVOLUTIONARY EPISTEMOLOGICAL PERSPECTIVE
}

\author{
Daniël P Veldsman \\ Department of Dogmatics and Christian Ethics \\ University of Pretoria
}

\begin{abstract}
For almost four decades (1969-2007), the dominant and persuasive story of the theological scholarship of Wentzel van Huyssteen, the James I McCord professor of Theology and Science at Princeton Theological Seminary, New Jersey, USA has been and still is the problem of rationality. This article sketches the evolvement of his argument of relating theological reflection to natural scientific knowledge by focusing on three literary key moment (texts) in the abovementioned period, and it indicates how Van Huyssteen argumentatively arrived at his current position in which he argues that evolutionary epistemology creates a natural space for postfoundationalism of which the performative praxis is found in transversal reasoning.
\end{abstract}

Key Words: Inter-disciplinarity, Postfoundationalism, Rationality, Wentzel van Huyssteen

\section{How to Tell and Why to Tell - That is the Hanging on Question!}

The theological quest of the South African born Wentzel van Huyssteen, the James I McCord professor of Theology and Science (since 1992) at Princeton Theological Seminary, New Jersey, USA can best be described - in his own words - as follows:

How, and why, do some of us hang on to some form of religious faith in the midst of the confusion of this fragmented postmodern age? How can we speak of the certainty of faith, of passionate commitments and deep convictions, in a postmodern cultural context that seems to celebrate cultural and religious pluralism with such abandon? Can Christian theology, as a disciplined reflection on religious experience, ever really claim to join this postmodern conversation, and if it does, will it be able to maintain its identity in the conversation without retreating to an esoteric world of private, insular knowledge claims? ... How does theological reflection relate to other modes of intellectual inquiry, and especially to natural scientific knowledge, which very often is accepted unchallenged as the ultimate paradigm of human rationality in our times? (Van Huyssteen 1997:1-2).

Since his first academic publication ${ }^{1}$ in 1969 , the dominant and persuasive story of his theological scholarship over almost four decades has been and still is the problem of rationality as reflected in the afore going quotation. In addressing this problem of models of rationality, objectivity, truth and theorizing within the contexts of the theology-science relationship, an exciting and promising story has evolved (spanning 1969-2007) of which the crystallised core could be summarized as follow:

Die geskiedenisteologie van Wolfhart Pannenberg (1969). A complete bibliography of Van Huyssteen's academic contribution can be found in the Festschrift edited by LeRon Shults (2006:418-422). 
Evolutionary epistemology creates a natural space for postfoundationalism. The performative praxis of postfoundationalism is found in transversal reasoning.

In this article, I would like to sketch the evolvement of Wentzel's argument in broad strokes which has led to the above formulation, focusing on three decisive literary key moments (texts). The three texts that I have identified as literary key moments are:

- Theology and the justification of faith [1986 (1989)]; ${ }^{2}$

- The shaping of rationality (1999) and

- Alone in the world? (2006). ${ }^{3}$

The mentioned texts ${ }^{4}$ - in my opinion - represent key evolving moments (which I henceforth call 'constructive' moments) in the understanding of Wentzel's scholarly quest for the integrity of theological reflection in telling the story of religious awareness with interdisciplinary integrity. In my unfolding of his story, I have gratefully made use of the outstanding short essay of Kenneth Reynhout (2006:1-16) on "The Evolution of Van Huyssteen's Model of Rationality" which was published in the Festschrift for Wentzel, edited by LeRon Shults (2006). ${ }^{5}$

\section{The Constructive Key Moment of 1986: Commitment to Experiential and Epistemological Adequacy}

In the nineteen articles and three books that Wentzel published up to 1986, he developed a rationality model which can be characterized as a 'weak' form of Critical Realism (CR). The CR model was his answer to the basic question, namely on how do we construct theories in theology (Van Huyssteen 1989:x-xviii)? Can this kind of theoretical reasoning ever be considered 'rational' in any significant sense, particularly when compared with the apparent rigour of the natural sciences? Wentzel argued that if theology is understood as a "critical account rendering of faith" that strives for relevance in the world, then theologians cannot evade the methodological, hermeneutical and epistemological issues that precede the forming of theological propositions. The question of relevance is formulated - as a contextual question - as follows:

In the South African context, especially, both dimensions the individual and the intersubjective experience of faith now lies at the core of what must surely be the most pressing theological question of our time: Can theology still speak out contextually in such a manner that the liberating voice of the gospel may be heard loudly and clearly in all facets of our society? (Van Huyssteen 1989:x).

In constructing his model of rationality for theology, Wentzel (1989:3ff) firstly turn to a critique of logical positivism, ${ }^{6}$ unmasking its ideological character and refuting its

Translation (1989) of Teologie as kritiese geloofsverantwoording (1986).

I am of the opinion that Wentzel's article for George Newlands' Festschrift Building effective bridges to culture: God and redemption in the work of Richard Wagner (2006) represents on a personal level another literary key moment that has to be read in conjunction with Alone in the world? In this paper I will however not explore this observation.

4 My choice of the three texts is supported amongst others by Stone (2006:73ff) and Gregersen (2006:306ff) in their respective contributions to the Festschrift.

5 In his insightful article, Reynhout (2006:1ff) concentrates on three phases in the evolution of Van Huyssteen's thought, namely 1970-1989, 1990-1999 and 2000-present. My own exposition in which I focus on the literary key moments, corresponds greatly with his identified three phases although I have turned my attention to the evolving key concepts in his pursuit of the problem of rationality.

6 The core of Logical Positivism can be described as follows: Through direct observation, facts must speak for themselves, neutrally and freely (cf Van Huyssteen 1989:9). 
methodological (positivistic) smugness which left - by implication - all metaphysicaltheological statements as cognitively meaningless. For the unmasking and refutation of positivism, Wentzel finds his philosophical ammunition in the socio-historical (Popper) and contextual (Kuhn) nature of scientific discovery and Larry Laudan's argument for a relative progress in science (Van Huyssteen 1989:24ff; 47ff; 173ff). Although they posed their very own challenges for theological reflection (which he simultaneously addresses in a rigourous dissection of the theological designs of Barth, Heyns, Bartley, Pannenberg and Sauter, see $11 \mathrm{ff}, 19 \mathrm{ff}, 33 \mathrm{ff}, 71 \mathrm{ff}$ and 101ff), Wentzel tackled them by starting - in dialogical interaction amongst others (eg Ernan McMullan, see 148ff, 188, 195ff; Sallie McFague, see 73ff, $131 \mathrm{ff}, 104 \mathrm{ff}, 163 \mathrm{ff}$ ) with interdisciplinary theology-science theoreticians (eg Peacocke, see 156ff) - to develop a set of minimal criteria for a credible model of theological rationality (Van Huyssteen 1989:143ff). He now explicitly identifies the problem of rationality as an essentially epistemological problem, believing that the "epistemological dimension must form the very foundation of all further methodological and thus also of all hermeneutical questions in theology" (Van Huyssteen 1989:xii), and his own position as a critical realist. ${ }^{7}$ In his own words:

A critical realist stand is realistic because in the process of theological theorizing this concept enables us to recognize this cognitive and referential nature of analogical languages as a form of indirect speech. It is also critical, however because the role of metaphoric language in theology would teach us that models should never be absolutized or ideologized, but should retain their openness and provisionality throughout the process of theorizing (Van Huyssteen 1989:142).

In developing his set of criteria (reality depicting, problem-solving ability, progressive, see page 146ff) for a credible Christian theology, he focuses on the origin of theological theories, and from there, on religious experience and religious language, concluding that they work together in the conceptualizing of theological models (Van Huyssteen 1989:125ff). For his developing model of rationality it simply implied that theological reflection had to be aware of the limits of religious language (that is, its metaphorical nature, see page 126ff, 132ff) and on how their contextual faith commitments shaped their reasoning. The latter recognition (that of contextual faith commitments, see 159ff) did not imply the negation of commitments, but rather that they could reach out responsibly across contextual borders and make valid, yet provisional inter-subjective theological statements in addressing conceptual and empirical problems. For these statements to be considered rational, the theologian had to engage both the theological reflective sources (the Bible, tradition, dogma and creedal formation, see 177ff) as well as contemporary scientific thought (see 186ff). And progress thus meant the ability of a theory to effectively answer the addressed theological problems (see 190ff).

In my opinion the key moment of the text of 1986 in addressing the problem of rationality, can be summarized in the short formulation, namely Wentzel's commitment to experiential and epistemological adequacy of theological reflection. ${ }^{8}$ Evolving from this

$7 \quad$ In an article published two years later and reprinted in Essays (1997), Wentzel points out that he is only willing to argue for a qualified and weak form of critical realism insofar as the referential claims are derived from a basic assumption and good reasons without the reasons being conclusive, and without the claim of a progressively convergent realism (Van Huyssteen 1997:167; cf Gregersen 2006:307).

8 This commitment can clearly be found in the concluding paragraph to this book in which Wentzel states in reference to 1 Cor 13:12 ("For now we see through a glass darkly, but then face to face") the following: "The tentative knowledge revealed for us in these simply images, as well as the hidden mysteries they preserve, is an essential part of the structure and tension of our religious language. The special task of systematic theology is to preserve that tension in creatively designing concepts, models, and finally theological 
moment, we find a broadening by Wentzel of the problem setting in which he as 'nonfoundationalist' (that is, searching for a non-fideist rational basis) turns 'postfoundationalist'.

\section{The Constructive Key Moment of 1999: The Fall from Epistemological Innocence and the Quest for Intelligibility}

In the period of 1986 to 1999 , Wentzel published a further 28 articles (quite a few however being re-publications) and six books (including the book he edited with Niels Gregersen), of which I take the Shaping of Rationality (1999) as the constructive key moment. He dedicates this book to his wife Hester, and in his dedication of the book to her, provides us with the personal motivation of his ongoing pursuit:

I dedicated it to her with love and appreciation. She was there when the problem of rationality began to haunt me, and she was there when it grew into a passion. That she put up with this, and that she could show me how the complexities of human rationality are deeply embedded in the joys and challenges of everyday life, has been an unforgettable lesson in what rationality really is about (Van Huyssteen 1999:xi).

Wentzel's 'being haunt' subsequently became his passion: What is rationality really about? The quest for adequacy that came from Wentzel's 'weak' CR position, now broadens into the realm of inter-disciplinarity, specifically of theology and science, and can best be captured in the question: 'Why rationality?' (Van Huyssteen 1999:1). In his own words:

It took me a long time ... to grasp that in trying to understand what scientific reflection is about, and in trying to understand what theological reflection is about, the answer is hidden in the understanding itself (Van Huyssteen 1999:1).

In pursuit of the "hidden answer in the understanding itself", Wentzel is adamant that science cannot claim rationality - that most unique of our human abilities - at the expense of religious faith and theological reflection (Van Huyssteen 1999:2). The broadening (that is, the identifying of shared rational resources) was accompanied by his questioning of the standard approaches for relating science and theology on the one hand and on the other hand by his argumentative insistence that both - theology and science - have lost their epistemological innocence. ${ }^{9}$ He argued that we should instead be exploring the epistemological questions of the nature of explanations and explanatory claims, operative in different disciplines (cf Reynhout 2006:8). His quest subsequently focuses on demonstrating how a postfoundationalist epistemology can negotiate the complex rational demands of the science and theology dialogue. Over against some forms of postmodern, non-foundationalist theology (which he accused of being 'neo-Wittgensteinian fideism') and 'antifoundationalism', he introduces a new term, namely 'post-foundationalism' to refer to his own attempt to split the difference between foundationalist certainty and non-foundationalist relativism by being contextual, yet inter-subjective, committed yet fallibilist, provisional yet explanatory. And with the postfoundationalist notion of rationality comes three 'eye openers' for Wentzel, namely:

theories, while nonetheless progressing through a problem-solving and thus maximally meaningful appeal to both our insight and our experience" (Van Huyssteen 1989:197).

9 This the question that Wentzel focused on in his earlier work, namely Duet or Duel? Theology and Science in a Postmodern World (1998), in which he argued that in the interdisciplinary conversation between theology and the sciences of cosmology and evolutionary biology rich resources can be found for retrieving an integrated approach to human knowledge that would neither be modernist nor foundationalist in nature. 
A postfoundationalist notion of rationality will therefore provide a quite unique link between theology and the sciences, and will open our eyes to:

- first, fully acknowledge contextuality and the embeddedness of both theology and the sciences in the different domains of human culture;

- second, affirm the epistemically crucial role of interpreted experience and the way that tradition shapes the epistemic and nonepistemic values that inform our reflection about God and world;

- third, at the same time creatively point beyond the confines of the local community, group or culture, toward plausible forms of transcommunal and interdisciplinary conversation (Van Huyssteen 1999:8-9).

In an insightful (rational) turn, Wentzel sharpens the range of the term 'rational' - following Rescher (cf Van Huyssteen 1999:155-61) and Brown (cf Van Huyssteen 1999:120-7; 142-150; 157-166) - by taking the rational agent (see also his earlier article The Shaping of Rationality in Science and Religion, 1997:238-265) under scrutiny and by claiming that there are common sources of rationality.

Regarding the former, he argues that it is first and foremost a quality of an individual's decision, and only derivatively about beliefs, propositions, or communities. Furthermore, he expands the idea of rationality beyond its obvious cognitive interpretation. Rationality involves a 'quest for intelligibility' involving a search for good reasons for hanging on to certain beliefs, good reasons for making certain moral choices, and good reasons for acting in certain ways (cf Van Huyssteen 1999:269). By acknowledging contextuality, the epistemic role of interpreted experience and how our values are shaped by tradition, Wentzel proposed that a postfoundationalists model of rationality could respond constructively to the postmodern critique of foundationalism.

Regarding the latter, Wentzel (Van Huyssteen 1999:174ff) identifies three sources of rationality (or epistemological overlaps), namely the quest for intelligibility (that is, a quest - shared by all the domains within which we form beliefs, make deliberate choices and act in particular ways - for optimal understanding that as survival strategy is a most important part of our evolutionary heritage), responsible judgment skills (that is, the back-and-forth process of personal judgment and inter-subjective accountability as contextual and crosscontextual movements) and progressive problem-solving (that is, a responsible theory choice and theory commitment).

The last important aspect regarding this key moment of Wentzel's evolving understanding of rationality, I find in his - following Calvin Schragg - utilization of 'transversal rationality' (that is, evaluative critique, engaged articulation and incursive disclosure) as an essential dynamic in his own postfoundational model of rationality. He explains:

Transversal rationality is not ... just a 'passage of consciousness' across a wide spectrum of experiences and held together by our memory. It is rather, a lying across, an extending over, a linking together, and an intersecting of various forms of discourse, modes of thoughts, and action.

And:

Transversal rationality thus emerges as a place in time and space where our multiple beliefs and practices, our habits of thought and attitudes, our prejudices and assessments, converge.

And thus:

What is at stake in this notion of transversality is to discover, or reveal, the shared resources of human rationality precisely in our very pluralist, diverse assemblages of 
beliefs or practices, and then to locate the claims of reason in the overlaps of rationality between groups, discourses, or reasoning strategies (Van Huyssteen 1999:136).

For the postfoundationalist Wentzel (Van Huyssteen 1997:136), a new and promising understanding of interdisciplinary dialogue now emerges: in interdisciplinary conversation the degree of transversality achieved will ultimately depend on the effectiveness of our dialogue across the boundaries of different domains, and on the (often fragile) understanding we achieve in our interaction with one another. ${ }^{10}$ This is what Wentzel puts to the 'test' in the next key moment which finds expression in being freed from epistemic narcissism and epistemological tribulism.

\section{The Constructive Key Moment of 2006: Freed from Epistemic Narcissism and Epistemological Tribulism}

Since 1999, Wentzel has published a further nine articles, an Indonesian translation of his book Duet or Duel (1998) was published, and he acted with Niels Gregersen, Nancy Howell and Wesley Wildman as editors for the impressive Encyclopedia of Science and Religion (2003). And then came along - in my opinion the next evolving key moment in his addressing of the problem of rationality - namely his Alone in the World? (2006). His evolved understanding of rationality has now brought him to the ultimate evolutionary origins of human rationality itself. This is the subsequent concrete unfolding of his argument ${ }^{11}$ in the preceding Duet or Duel (1998) in which Wentzel states:

Evolutionary epistemology ... reveals the biological roots of all human rationality and should therefore lead precisely to an interdisciplinary account of our epistemic activities. The basic assumption of evolutionary epistemology is that we humans, like all other beings, result from evolutionary processes and that, consequently, our mental capacities are constrained and shaped by the mechanism of biological evolution (Van Huyssteen 1998:xiii-iv).

This interdisciplinary account ${ }^{12}$ finds concrete expression in two related endeavors, both culminating in two specific epistemological liberations, namely:

- his attempt at developing a comprehensive epistemology that is rooted in the biological origins of human rationality as understood by evolutionary epistemologists, and

- his exploration of human uniqueness from both theological and scientific perspectives.

The first endeavor opens up the conviction that all knowledge is biologically rooted, and that all knowledge is grounded in human evolution. He thus argues that the common biological origin of all forms of knowledge reveals a universal intent that links together all our diverse and complex epistemic activities. This endeavor culminates in the liberation from epistemic narcissism. In the second related endeavor, Wentzel grapples with the challenge posed by the process of human evolution for our understanding of human uniqueness. This endeavour culminates in the liberation from epistemological tribulism. This

10 See the insightful unpublished paper by Kenneth Reynhout on The Hermeneutics of Transdisciplinarity: A Gadamerian Model of Transversal Reasoning (2007) in which he explores "transversal reasoning" as in his own words "intriguing idea that still requires further explanation” (Reynhout 2007:1).

11 I follow here Reynhout (2006:12) who has made the insightful connection between Van Huyssteen's earlier Duet or Duel and his later Gifford Lectures.

12 In a footnote, Reynhout (2006:13) makes the important remark that crucial to Van Huysteen's argument against a Dawkins-like reductionism of religious awareness is the distinction that he draws (following Wuketis) between "organic" and cultural evolution, the latter being based in the former but not reducible to it. This remark should be kept in mind regarding Wentzel's understanding of the ultimate evolutionary origins of human rationality. 
found expression in his Gifford Lectures at the University of Edinburgh, Scotland (2004), published in 2006 as Alone in the World? ${ }^{13}$

Taking as vantage point his now substantiated and established conviction that the domain of religious faith and the domain of scientific thought share in the resources of human rationality and are therefore able to be linked in interdisciplinary dialogue (Van Huyssteen 2006:1-43), Wentzel links the question of human uniqueness to evolutionary epistemology (with a special focus on the prehistory of the human mind). It unfolds as a multidimensional interdisciplinary discourse in which perspectives from theology, epistemology and the sciences meet along diversely intersecting lines (Van Huyssteen 2006:45109), arguing conclusively that evolutionary epistemology clearly shows that a human propensity for metaphysical and religious belief should be seen as the result of specific interactions between early humans and their lifeworlds. Subsequently Wentzel shifts the focus to one of the core traditions of the Christian faith, namely the doctrine of the imago Dei (Van Huyssteen 2006:111-162), arguing that the porousness of the boundaries between theology and the sciences allows for a creative (two-pronged) rethinking of this notion in Christian theology. On the one hand, the relative convergence of theological and scientific arguments on the issue of human uniqueness gives us according to Wentzel an argument for the plausibility and comprehensive nature of religious and theological explanations for a phenomenon as complex as Homo Sapiens (Van Huyssteen 2006:113ff). At the same time, on the other hand, Wentzel argues that scientific notions of human uniqueness helps us to ground theological notions of human distinctiveness in the reality of flesh-and-blood, reallife, embodied experiences, and thus protect theological reflection from overly complex abstractions when trying to revision the notion of the imago Dei. Taking his own argument now concretely seriously, Wentzel subsequently turns his revision to a neglected voice on this crucial issue, namely contemporary paleoanthropology ${ }^{14}$ (Van Huyssteen 2006:163215), showing that the prehistory of the human mind (including the evolution of consciousness and self-awareness) reveals the remarkable cognitive fluidity (a concept that he has taken over from Steven Mithen ${ }^{15}$ of our mental abilities. With three distinct disciplinary lines (evolutionary biology, theology and paleoanthropology ${ }^{16}$ ) of argument on human uniqueness now transversally intersecting, Wentzel (Van Huyssteen 2006:217ff) not only evaluates the intersecting of the three lines, but 'thickens the (intersecting) plot' by introducing new interdisciplinary proposals (drawing on linguistics, neuroscience and neuropsychology).${ }^{17}$ From this evaluation, Wentzel argues that:

13 Reynhout (2006:14-15) rightly remarks: “Alone in the world? is impressive, not only for its comprehensive treatment of various scientific and theological perspectives on human uniqueness, but also for the way in which Van Huyssteen attempts to stay true to his own postfoundationalist, interdisciplinary methodology". See also the interesting comments by Dixon (2006:5-6) and the good book review by Flanagan (2007). In his concluding remark, Flanagan (2007:5) states that the book makes a significant contribution to theological methodology and to the contemporary dialogue between science and religion.

14 According to Van Huyssteen (2006:168ff), the materiality of these prehistoric images (eg hand prints, bird man, wounded men etc) that are to be found in the Paleolithic cave art in southwestern France and the Basque Country in northern Spain, might not tell us much about our remote human or hominid origins, but the images certainly reveals much of what it means to be human, and as such, dramatically reveal the complexity of the cognitively fluid human mind. See, however, the interesting and critical questions which are raised by Kevin Sharpe and Leslie van Gelder (2006) regarding Van Huyssteen's interpretations of these images.

15 Cognitive fluidity is evidenced by the human capacity for imagination, creativity, and symbolic thought, which in turn are prerequisites for the emergence of science, art, and religion (cf Reynhout 2006:13).

16 The three distinctive disciplinary lines are namely the epistemological argument from evolutionary biology, the historically diverse and rather fragmented argument from theology, and the complex, multileveled scientific argument from contemporary paleoanthropology.

17 The focus of his evaluation of the (intersecting) "plot" is on the question as to how symbolic representation, as 
- the capacity for spirituality can be understood as an emergent consequence of the symbolic transformation of cognition and emotions, thus explaining why the propensity for religion and religious experience can be regarded as an essentially universal human attribute (Van Huyssteen 2006:233ff );

- a postfoundationalist approach to human uniqueness as an interdisciplinary problem should alert us to the fact that religious imagination cannot be discussed abstractly or treated as a generic given, but can be discussed and evaluated only within the concrete context of specific religions and concrete theologies (Van Huyssteen 2006:261ff), and

- theologians should revisit the way notions of the imago Dei are constructed since interpretations thereof have indeed varied dramatically throughout the long history of Christianity (Van Huyssteen 2006:267-270; 271ff).

To summarise and conclude: In his interdisciplinary proposal on human uniqueness, Wentzel argues that theologians must rethink personhood in terms of imagination, symbolic propensities, and cognitive fluidity that acknowledges humanity's close ties with the animal world. He develops theories of the imago Dei that recognizes that this quality has emerged by natural evolutionary processes and suggests that we reconceive of the imago Dei in a highly, contextualized, embodied sense (cf Van Huyssteen 2006:276ff). Staying true to his postfoundationalist, interdisciplinary methodological position, and freed from epistemic narcissism and epistemological tribulism, Wentzel thus ultimately substantiates his 'transversal exercise' that theology can engage in rational discourse across interdisciplinary lines.

\section{Conclusion: Transgressing Boundaries as Adventurous Non-transgressors}

If I briefly had to formulate Wentzel's journey to interdisciplinarity over almost four decades of the finest and most sophisticated intellectual scholarship, I would name the following as beacons along his 'liberating' story of rationality, namely his commitment to experiential and epistemological adequacy; a commitment which led to the fall from epistemological innocence and the quest for intelligibility, culminating in the liberation from epistemic narcissism and epistemological tribulism. It is a journey that can now be summarized in an insightful manner as follow:

Evolutionary epistemology creates a natural space for postfoundationalism. The performative praxis of postfoundationalism is found in transversal reasoning.

Perhaps LeRon Schults (2006:xiii), a former student of Wentzel, describes the contagious and explorative enthusiasm that rubs off from Wentzel's intellectual scholarship best by saying:

During my sojourn at Princeton, my fellow doctoral students and I were welcomed to transgress the boundaries of the disciplines in his seminars but never made to feel like transgressors.

Indeed. Wentzel's adventurous and intellectual exercise in transversal reasoning has transgressed many traditional boundaries for the sake of telling the (fuller) religious (Christian) story with integrity. It is a story of transgression that comes to us as an invitation and, if accepted, does not make one feel like a transgressor. Instead, it is an experience of intellectual liberation, of good reasons for passionately hanging on!

the principal cognitive signature of humans, is grounded in our remarkable mimetic and linguistic abilities (cf Van Huyssteen 2006:233ff). 


\section{BIBLIOGRAPHY}

Dixon, Thomas 2006. "The Carbon and the Christian" (Dec 20, 2006). Times OnLine. TLS (see http://tls.timesonline.co.uk/article).

Flanagan, John 2007. Review: "Alone in the world? Human Uniqueness in Science and Theology". Australian EJournal of Theology (see http://dlibrary.acu.edu.au/research/theology/ejournal/aejt 10/bookreviews.htm).

Gregersen, Niels H 2006. "What Theology might learn (and not learn) from Evolutionary Epistemology: A postfoundationalist Theologian in conversation with Pascal Boyer", in: Shults, LeRon (ed.) 2006.

Reynhout, Kenneth A 2006. "The Evolution of van Huyssteen's Model of Rationality”, in: Shults, LeRon (ed.) 2006.

Reynhout, Kenneth A 2007. "The Hermeneutics of Transdisciplinarity: A Gadamerian Model of Transversal Reasoning". Unpublished paper read at the program (2-6 June 2007) of the Metanexus Institute, Philadelphia, USA on "Transdiciplinarity and the Unity of Knowledge".

Schults, LeRon F (ed.) 2006. The Evolution of Rationality. Interdisciplinary Essays in Honor of J. Wentzel van Huyssteen. Grand Rapids, Michigan: Eerdmans.

Sharpe, K \& Van Gelder, L 2006. "Human uniqueness and Upper Paleolithic 'Art': An archaeologist's reaction to Wentzel van Huyssteen's Gifford Lectures" (see http://www.ksharpe.com?Word/AR97.htm).

Stone, Jerome A 2006. "Van Huyssteen in context: A comparison with Philip Hefner and Karl Peters", in: Shults, LeRon (ed.) 2006.

Van Huyssteen Wentzel 1986. Teologie as kritiese geloofsverantwoording. Pretoria: RGN.

Van Huyssteen Wentzel 1997. Essays in Postfoundationalism. Grand Rapids, Michigan: Eerdmans.

Van Huyssteen Wentzel 1998. Duet or Duel? Harrisburg: Trinity Press International.

Van Huyssteen Wentzel 1999. The Shaping of Rationality. Toward Interdisciplinarity in Theology and Science. Grand Rapids. Michigan: Eerdmans.

Van Huyssteen Wentzel 2006. "Building Effective Bridges to Culture: God and Redemption in the Work of Richard Wagner". (Forthcoming in Newlands' Festschrift).

Van Huyssteen Wentzel 2006. Alone in the World? Grand Rapids, Michigan: Eerdmans.

Van Huyssteen, Wentzel 2007. "A Brief Overview of a Theologian's Journey to Interdisciplinarity”. Unpublished document. 